\title{
OSTEOID OSTEOMA OF THE ATLAS
}

\author{
DAVID ANTHONY JONES
}

Osteoid osteoma of the spine is rare and the following case of a classic osteoid osteoma in the arch of the atlas may be unique.

An 8-year-old boy presented in September 1985 with a painful neck and restriction of neck movement, both of which had come on insidiously over a period of three months. On examination he had a torticollis with the head rotated to the right; rotation to the left produced pain. He was diffusely tender on deep palpation of the upper cervical spine. There was no facial asymmetry, no history of significant trauma, no sternomastoid spasm or mass, and no abnormal neurological signs.

Plain radiographs were normal and radiographic screening demonstrated spasm, but no other abnormality. A technetium bone scan demonstrated a hot spot in the posterior part of the atlas (Fig. 1). Treatment with aspirin relieved his pain and improved his movements.

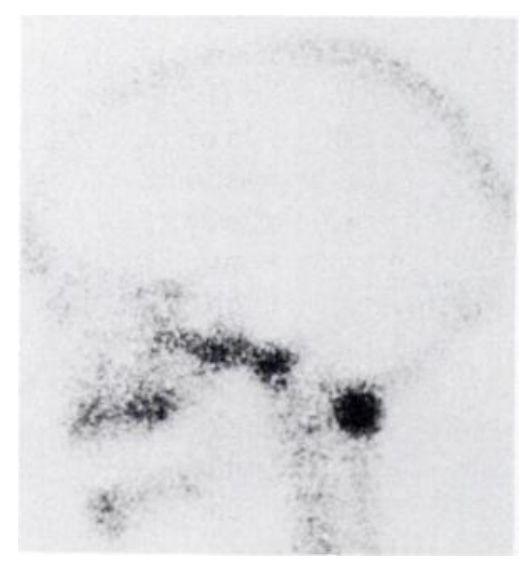

Fig. 1

During this treatment computerised tomography was carried out and showed that the lesion, in the posterior arch of the atlas, contained a small nidus (Fig. 2). In December 1985 the lesion was excised; completeness of removal was ensured by using an intra-operative radiation-detecting probe (Colton and Hardy 1983). By February 1986 the patient's neck movements were greatly improved and his pain completely relieved.

D. A. Jones, FRCS, FRCS Ed, Consultant Orthopaedic Surgeon Morriston Hospital, Swansea SA6 6NL, Wales.

(C) 1987 British Editorial Society of Bone and Joint Surgery $0301-620 X / 87 / 1$ R $19 \$ 2.00$

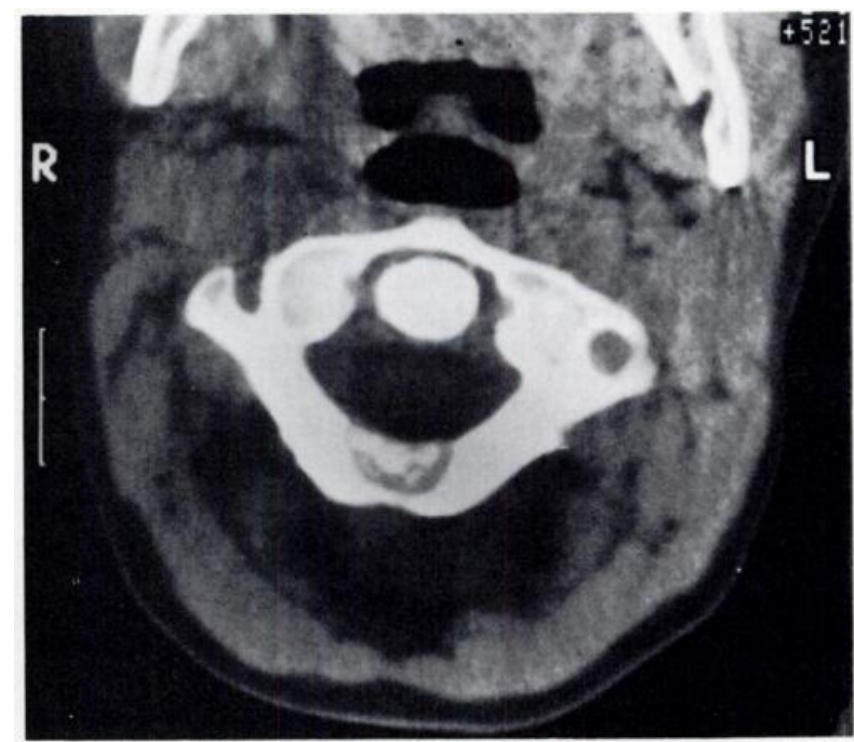

Fig. 2

Discussion. There are three problems in the management of osteoid osteoma of the spine: delay in diagnosis; accurate localisation; and ensuring complete removal.

Early diagnosis is enhanced by isotope scanning all cases of unexplained spinal spasm; computerised tomography is very helpful in localising the lesion accurately (Nelson and Greer 1983); and a sterilisable radiationdetecting probe helps both accurate localisation and complete removal. In the case described, detecting the lesion was fairly easy, but ensuring complete extirpation was difficult. At one stage it looked as if the lesion had been completely removed, but the probe continued to give high readings to the right of the excised area. Further excision was therefore carried out until low background readings were obtained.

Isotope scanning, computerised tomography, and the use of a sterilisable radiation probe are therefore recommended in the management of such cases.

\section{REFERENCES}

Colton CL, Hardy JG. Evaluation of a sterilizable radiation probe as an aid to the surgical treatment of osteoid osteoma: technical note. $J$ Bone Joint Surg [Am] 1983;65-A :1019-22.

Nelson OA, Greer RB III. Localization of osteoid-osteoma of the spine using computerized tomography: a case report. J Bone Joint Surg [Am] $1983 ; 65-\mathrm{A}: 263-5$. 